\title{
PERANCANGAN RUMAH SAKIT UMUM BERKONSEP HEALING ENVIRONMENT DI KECAMATAN CILEUNGSI
}

\author{
Atiek Fajriati, Soepardi Harris, Karya Widyawati \\ Program Studi Arsitektur, Fakultas Teknik, Matematika, dan Ilmu Pengetahuan Alam \\ Universitas Indraprasta PGRI
}

\begin{abstract}
Abstrak
Fenomena yang sering terjadi, Rumah Sakit menjadi tempat yang bisa memberikan rasa takut dan tidak nyaman bagi pasien. Selain itu, faktor psikologi juga sering diabaikan karena dianggap tidak begitu penting. Faktor medis bukanlah satu-satunya Psikologi lingkungan merupakan bagian dari Healing Environment yang membantu penyembuhan pasien lewat lingkungan yang dapat berpengaruh pada psikis pasien. Perancangan Rumah Sakit ini berlandaskan pada sebuah konsep tematik Healing Environment dimana dalam perancangan ini, proses penyembuhan pasien tidak hanya didapatkan melalui pihak medis tetapi juga didapatkan dari bangunan yang digunakan oleh pasien sebagai objek rancangan. Rancangan Rumah Sakit Umum Kelas B berkonsep Healing Environment bertujuan untuk menggali dan merumuskan masalah yang berkaitan dengan perencanaan dan perancangan Rumah Sakit melalui survei yang dilakukan, sehingga dapat diwujudkan suatu landasan yang konseptual bagi perancangan Rumah Sakit yang nyaman dengan menerapkan unsur-unsur yang harus dipenuhi dalam pembangunan Rumah Sakit Umum dengan pendekatan Phsycology Environment.
\end{abstract}

Kata Kunci : Kecamatan Cileungsi, Rumah Sakit Umum, Healing Environment

\begin{abstract}
The phenomenon that often happens, the hospital becomes a place that can provide fear and discomfort for patients. In addition, psychological factors are also often overlooked because it is considered not so important. Medical factors are not the only environmental Psychology is part of the Healing Environment that helps the healing of patients through the environment that can affect the patient's psychic. Hospital design is based on a thematic concept of Healing Environment where in this design, the patient's healing process is not only obtained through the medical side but also obtained from the building used by the patient as a design object. The design of Class B General Hospital with Healing Environment concept is aimed at exploring and formulating problems related to hospital planning and design through surveys conducted, so that it can be realized a conceptual foundation for the design of a comfortable Hospital by applying the elements that must be met in construction of General Hospital with Phsycology Environment approach.
\end{abstract}

Keywords: District Cileungsi, General Hospital, Healing Environment 


\section{PENDAHULUAN}

\section{Latar Belakang}

Pada setiap daerah. keberhasilan pembangunan dalam bidang kesehatan ditentukan oleh tinggi-rendahnya angka kematian dan variasi jenis penyakit yang di derita serta ditunjang dengan ketersediaan tenaga dan sarana kesehatan yang memadai. Rumah sakit merupakan sebuah bangunan yang memiliki kaidahkaidah yang berlaku secara khusus yang disesuaikan dengan jenis, tujuan dan fungsi khusus nya sebagai rumah sakit. Perancangan rumah sakit harus sesuai juga dengan kebutuhan pasien, baik dari segi medis maupun non medis yang dapat memberikan kesan aman dan nyaman bagi pasien. Terkait berpengaruhnya peran dalam proses penyembuhan pasien, maka seharusnya faktor lingkungan bisa mendapat perhatian utama dalam desain suatu fasilitas pelayanan kesehatan. Dalam upaya meningkatkan pelayanan kesehatan di Kecamatan Cileungsi.

\section{Tinjauan Teori}

Pengertian Rumah Sakit

Menurut Undang-Undang Republik Indonesia Nomor 44 Tahun 2009. Rumah sakit adalah sebuah institusi perawatan kesehatan yang menyediakan tempat untuk pasien rawat inap dalam jangka waktu tertentu. Rumah sakit biasanya didirikan berdasarkan wilayah oleh suatu organisasi/lembaga kesehatan (baik profit maupun non-profit), badan asuransi maupun badan amal termasuk donatur secara langsung bahkan organisasi keagamaan individu atau yayasan.

Klasifikasi Rumah Sakit berdasarkan jenisnya

Menurut ( Siregar dan Amalia, 2011) klasifikasi Rumah Sakit dibagi menjadi 5 bagian, yaitu sebagai berikut:

1. Rumah Sakit Umum

2. Rumah Sakit Khusus/Terspesialisasi
3. Rumah Sakit Penelitian/Pendidikan

4. Rumah Sakit Lembaga/Perusahaan

5. Klinik atau Puskesmas

Klasifikasi Rumah Sakit berdasarkan kepemilikannya

Menurut Permenkes RI Nomor 986/Menkes/Per/11/1992 Rumah Sakit berdasarkan kepemilikannya terbagi menjadi 2, yaitu :

1. Rumah Sakit Pemerintah

2. Rumah Sakit non Pemerintah (Swasta)

Klasifikasi Rumah Sakit Umum Swasta Menurut Keputusan Menteri Republik Indonesia No.806b/Menkes/SK/XII/1987 Rumah Sakit Umum swasta memiliki 3 klasifikasi, yaitu sebagai berikut:

1. Rumah Sakit Umum Swasta Kelas Pratama

2. Rumah Sakit Umum Swasta Kelas Madya

3. Rumah Sakit Umum Swasta Kelas Utama

Klasifikasi Rumah Sakit Umum berdasarkan Kelasnya

Menurut (Siregar dan Amalia, 2004) klasifikasi Rumah Sakit berdasarkan kelasnya terbagi menjadi 5,yaitu :

1. Kelas A adalah rumah sakit umum yang memberikan pelayanan kesehatan lebih dari 1000 tempat tidur.

2. Kelas B adalah rumah sakit umum yang memberikan pelayanan dengan fasilitas dan kemampuan pelayanan medik yang spesialistiknya 11 (sebelas) spesialistik dasar, dan terbagi menjadi 2 yaitu kelas B1 dan B2

3. Kelas $\mathrm{C}$ adalah rumah sakit umum yang memberikan pelayanan dengan fasilitas dan kemampuan pelayanan medik yang spesialistiknya sekurang- 
kurangnya 4 (empat) spesialistik dasar dengan jumlah kapasitas 100 400 tempat tidur

4. Kelas D adalah rumah sakit umum dengan kemampuan hanya memberikan pelayanan medik umum dan gigi. Kapasitas tempat tidur kurang dari 100.

5. Kelas E adalah rumah sakit khusus yang hanya memberikan satu macam pelayanan kedokteran saja.

Maka yang menjadi objek rancangan adalah rumah sakit umum swasta kelas B1 yang melayani 11 (sebelas) spealistik pelayanan medik dengan kapasitas 300-500 tempat tidur.

\section{Pengertian Rumah Sakit Healing Environment}

Kata "healing" diartikan sebagai sebuah keselarasan antara pikiran, tubuh, dan jiwa. Dan kata "environment" diartikan sebagai perilaku terjadi yang mencakup lingkungan potensial dan aktual. Dengan demikian Healing Environment merupakan sebuah lingkungan yang dirancang untuk menciptakan keharmonisan antara pikiran, tubuh, dan jiwa.(Laurens, 2004)

Pendekatan Desain Healing Environment Menurut Murphy (2008), ada tiga pendekatan yang digunakan dalam mendesain Rumah Sakit Healing Environment, yaitu alam, indra dan psikologis.

\section{Alam (Nature)}

ada beberapa jenis taman di dalam rumah sakit, yaitu contemplative garden, restorative garden, healing garden, enabling garden dan therapeutic garden. Contemplative garden dapat menenangkan pikiran dan memperbaiki semangat. Restorative garden dapat membuat perasaan orang yang sakit menjadi lebih baik.
Healing garden mengacu pada berbagai fitur taman yang memiliki kesamaan dalam mendorong pemulihan stres dan dapat memberikan pengaruh positif pada pasien, pengunjung dan staff rumah sakit. Therapeutic garden merupakan sebuah taman yang mencoba meningkatkan terapi medis lingkungan di dalam kondisi pengobatan medis. Enabling garden merupakan taman yang memungkinkan semua orang berbagai usia bisa menikmati dan berinteraksi.

2. Indera (Sense)

$$
\text { Panca Indra meliputi }
$$
pendengaran, penglihatan, peraba, penciuman dan perasa.

a. Indra pendengaran : pasien bisa mendapatkan ketenangan melalui suara-suara yang menyenangkan, misalnya suara musik, hal tersebut bisa mengurangi tekanan darah dan detak jantung dengan menciptakan sensasi kenikmatan yang mempengaruhi sistem saraf. yang dapat mengobati depresi, menenangkan pikiran, dan bersantai bagi anak-anak autis maupun pasien kejiwaan, sedangkan gemericik air terjun atau air mancur, dapat mempengaruhi energi spiritual dan bisa membangkitkan perasaan

b. Indra pengelihatan : melalui lukisan alam, penataan cahaya buatan lewat lampu, dan penataan warna sangat bisa membuat mata menjadi relaks atau santai.

c. Indra peraba : melalui sentuhan seorang pasien dapat menegaskan apa yang dilihat, dicium dan dirasa dalam sebuah proses penjelajahan. 
d. Indra penciuman : lewat aroma wewangian tumbuhan terbukti bisa menenagkan pikiran dan memacu detak jantung untuk kembali bersemangat, sedangkan aroma bau yang tidak sedap dan menyengat dapat meningkatkan gangguan pernapasan bagi penderita asma.

e. Indra perasa : bagi pasien akan sangatn merasa terganggu ketika mengalami sakit ataupun menjalani pengobatan karena berubahnya rasa makanan maupun minuman yang dikonsumsi. Oleh karena itu, kualitas makanan dan minuman yang dikonsumsi harus diperhatikan.

\section{Psikologi (Phsycology)}

Secara psikologis, perawatan pasien diberikan dengan memperhatikan pilihan, terhadap kebutuhan dan nilai-nilai yang bisa menuntun keputusan klinis pasien. Sehingga Healing Environment dapat membantu proses pemulihan pasien, mengurangi rasa sakit dan depresi atau stress.

\section{METODE PERANCANGAN}

\section{Data Primer}

Dalam perancangan ini, digunakan pendekatan melalui beberapa aspek berikut: - Pendekatan melalui kajian tipologi objek

1. Pendekatan melalui kajian tapak dan lingkungannya Pendekatan ini, perlu dilakukan analisis pemilihan site

2. Pendekatan terhadap penerapan Healing Environment pada objek rancangan dapat membantu proses upaya penyembuhan yang dilakukan.

3. Objek rancangan membutuhkan lingkungan yang membantu proses penyembuhan pasien supaya dalam jangka waktu perawatan yang minim, selain itu proses penyembuhan pasien lebih optimal. Konsep Healing Environment dirasa sangat serasi dengan kebutuhan objek rancangan. Penulis berharap hal tersebut bisa membantu pihak medis dalam proses penyembuhan pasien.

4. Tinjauan Proyek Sejenis

Untuk mendapatkan data terkait, dilakukan tinjauan proyek sejenis dengan objek dan tema perancangan pada beberapa perancangan Rumah Sakit. Studi ini dilakukan agar penerapan perancangan objek pada bangunan Rumah Sakit Umum terancang dengan baik sesuai dengan tema dan konsep tanpa menghilangkan standar-standar ruangan yang ada pada bangunan Rumah Sakit. Metode ini dilakukan dengan pengambilan unsur-unsur perancangan yang bemilai positif dalam objek tinjauan dan memasukanya dalam desain rancangan baru yang direncanakan.

\section{Data Sekunder}

Data sekunder berupa data atau informasi yang mendukung program perancangan Rumah Sakit Umum Kelas B. Data ini di dapat dari studi literatur atau sumber tertulis yang berhubungan dengan perancangan. Studi tersebut diantaranya adalah sebagai berikut :

1. RDTR yang berisi kondisi umum, rencana penataan pada wilayah yang berisi potensi dan peta kawasan.

2. Studi pustaka bertujuan untuk mendapatkan data dan teori yang terkait dengan perancangan, di antaranya adalah :
a. Literatur tentang definisi dan fungsi bangunan Rumah Sakit
b. Literatur tentang peraturan bangunan Rumah Sakit
c. Literatur tentang konsep Healing Environment pada Rumah Sakit 
d. Serta literatur yang berasal dari data internet, buku dan majalah yang berisi hal-hal yang berhubungan dengan perancangan

\section{Studi Komparatif}

Studi komparatif membahas mengenai studi mengenai penataan pola ruang, bentuk yang berkaitan langsung dengan objek.
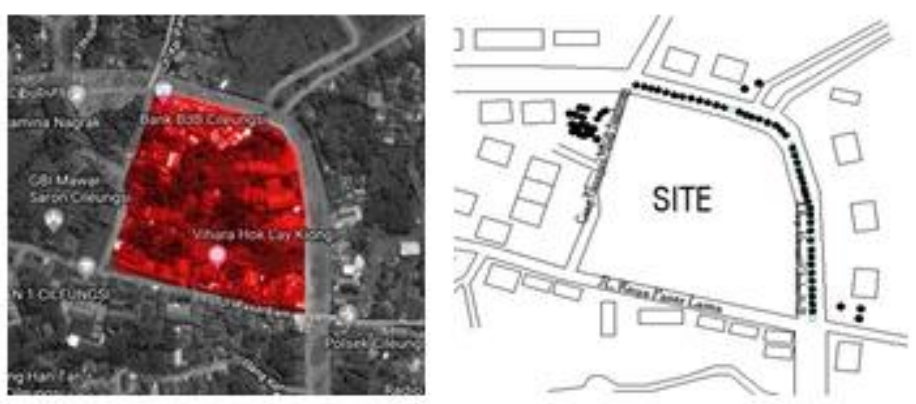

Gambar1. Lokasi dan layout tapak

\section{Konfigurasi Tapak}

Pola perletakan/orientasi masa bangunan serta sirkulasi tapak akan di bagian selatan sebagai pintu masuk karena menghindari penyinaran matahari secara langsung dan mengambil view yang menghadap ke wilayah Kecamatan Cileungsi.

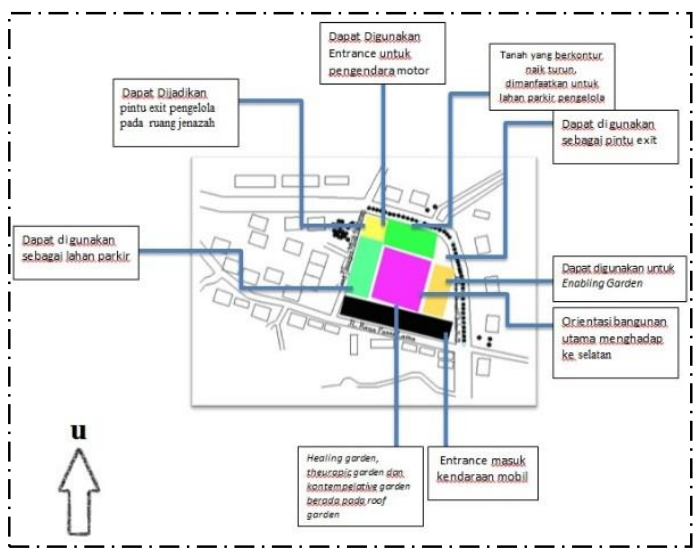

Gambar 2. Konfigurasi Tapak

\section{PEMBAHASAN DAN HASIL PERANCANGAN}

\section{Tinjauan Tapak}

Lokasi pembangunan Rumah Sakit Umum berada di Jalan Raya Alternatif Cibubur No. 21. Site berada didekat kawasan Pasar Lama Cileungsi, tapak dikelilingi berbagai macam bangunan dengan fungsi yang berbedabeda mulai dari komersial, hingga hunian. 
Zonasi berdasarkan privasi kegiatan terdiri dari :

1. Area publik, yaitu area yang memiliki akses langsung dengan lingkungan luar rumah sakit, seperti : IGD, poliklinik, apotek

2. Area semi publik, merupakan area yang menerima beban kerja dari area publik, misalnya radiologi, laboratorium, CT-Scan, rehabilitasi medik.

3. Area privat, yaitu area yang tertutup dan dibatasi oleh pengunjung rumah sakit, seperti : ICU/ICCU, PICU/HCU, Sterilisasi, CSSD, instalasi bedah, instalasi kebidanan dan penyakit kandungan, ruang rawat inap.

Zoansi berdasarkan pelayanan terdiri dari:

1. Zona pelayanan medik dan perawatan terdiri dari : Instalasi Gawat Darurat (IGD), Instalasi Rawat Inap, Instalasi Rawat Jalan, Instalasi Perawatan Intensif (ICU/ICCU/PICU/NICU), Instalasi Kebidanan dan Penyakit Kandungan, Instalasi Bedah, Instalasi Rehabilitasi Medik (IRM).

2. Zona penunjang dan Operasional : Instalasi Farmasi, Instalasi Radiodiagnostik, Laboratorium, Instalasi Sterilisasi Pusat (;Central Sterilization Departement/CSSD), Supply Laundri, Pemulsaran Jenazah, Instalasi Sanitasi, Instalasi Pemeliharaan Sarana Prasarana

3. Zona penunjang umum dan administrasi, terdiri dari : kesekertariatan dan akuntansi, rekam medik, logistik/gudang, perencanaan dan pengembangan (Rembang)

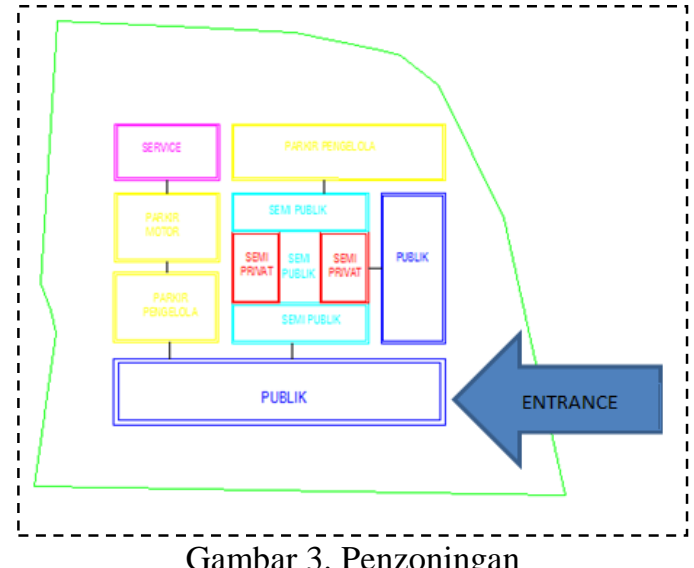

Gambar 3. Penzoningan

\section{Transformasi Bentuk}

Bentuk bangunan terjadi karena diambil dari tema perancangan yaitu Arsitektur Modern yang memiliki karakteristik bentuk dasar geometri (platonic solid) yang ditampilkan apa adanya (Banham Rayner, Guide To Modern Architecture, 2003)

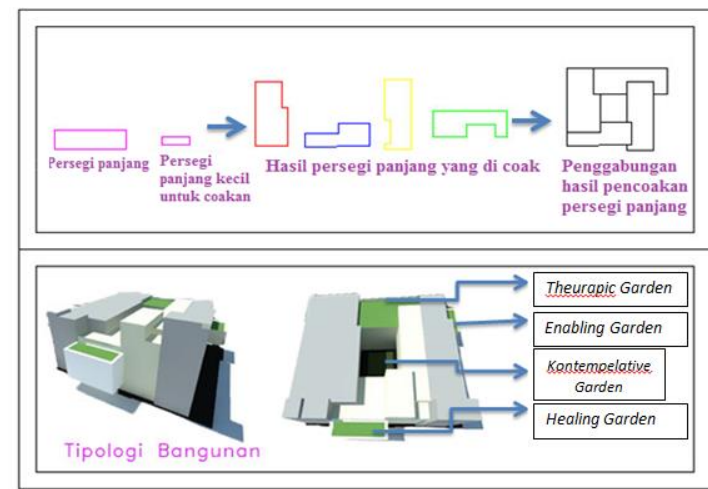

Gambar 4. Transformasi Bentuk dan Tipologi Bangunan

\section{Desain}

Konsep Penerapan Healing Environment Berikut ini ada beberapa poin penerapan Healing Environment dalam perancangan:

1. Warna

Secara psikologis tubuh kita sangat peka terhadap warna. Setiap warna dapat memberikan dampak yang berbeda-beda dalam sebuah desain Healing Environment. Biasanya dunia medis menggunakan warna 
yang lembut (soft) atau yang mendekati unsur alam.

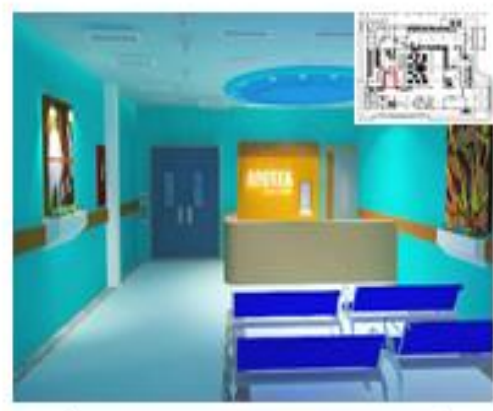

Ruang Tunggu Apotek

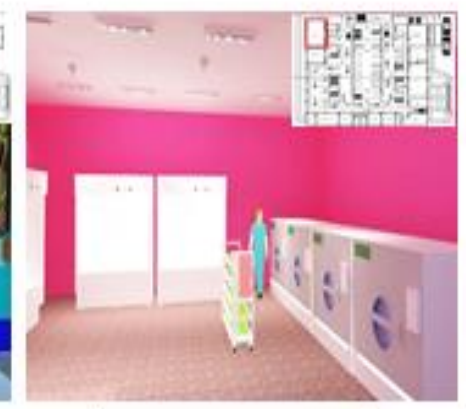

Ruang Laundry

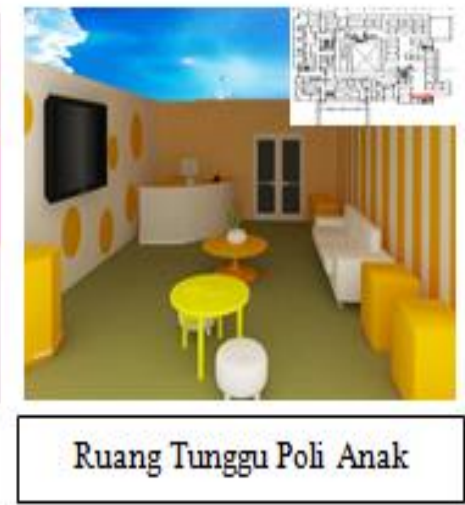

Ruang Tunggu Poli Anak

Gambar 5. Gambar Interior Ruangan

2. Unsur Alam dalam bangunan

Selain solusi dari permasalahan pada kondisi iklim, roof garden difungsikan sebagai taman untuk penyembuhan pasien lewat lingkungan yang akan berdampak pada Phsycology Pasien.
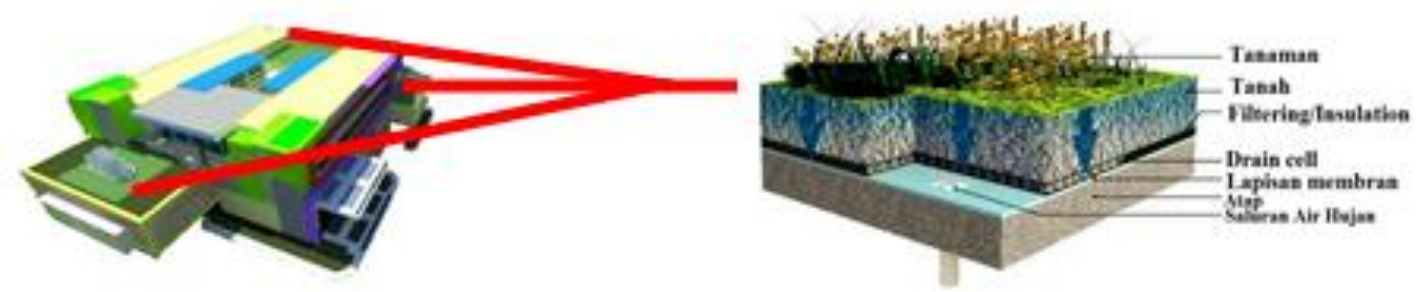

Gambar 5. Konsep Roof Garden

3. Pencahayaan

Pencahayaan alami dapat diperoleh melalui bukaan yang terdapat pada konsep Sky Light yang terdapat ditengah bangunan. Pencahayaan alami dapat mengurangi kecemasan psikis seseorang dan dapat mendorong emosi positif seseorang.

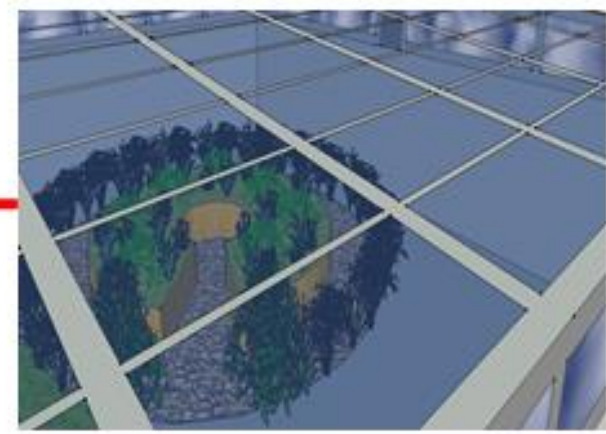

Gambar 6. Konsep Skylight 

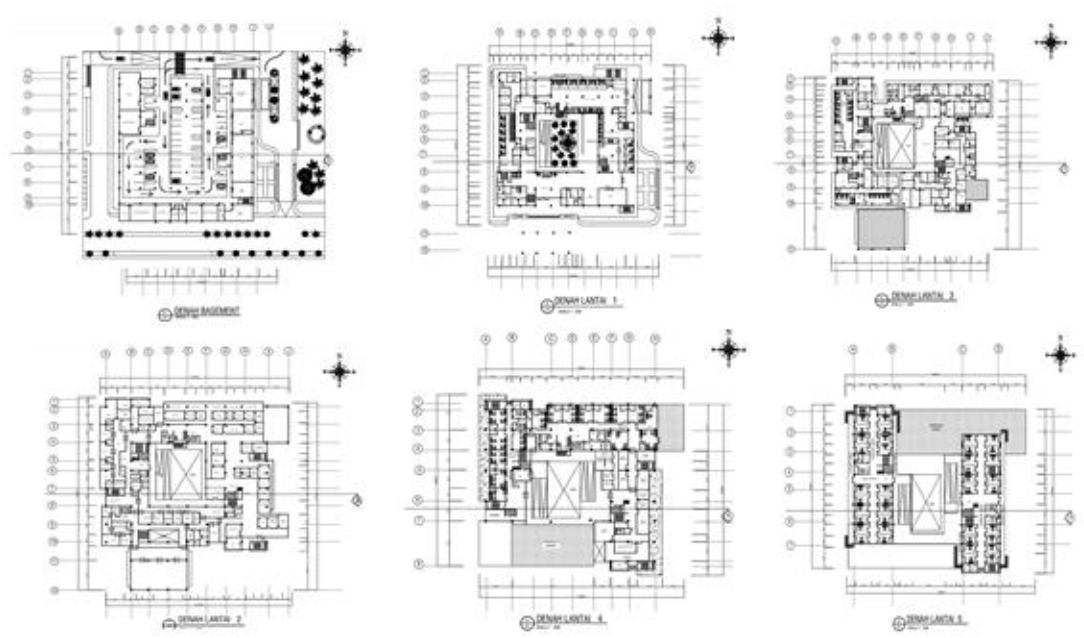

Gambar 7. Gambar Denah

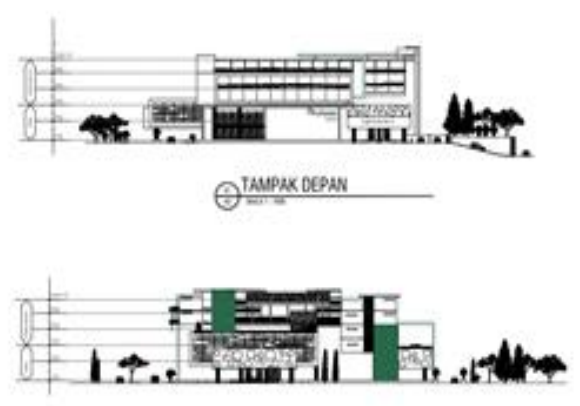

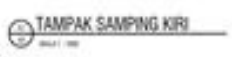

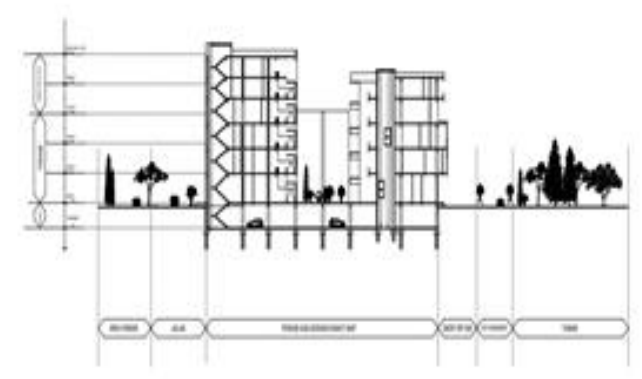

(2) Potongan 1.1

Gambar 8. Gambar Tampak dan Potongan
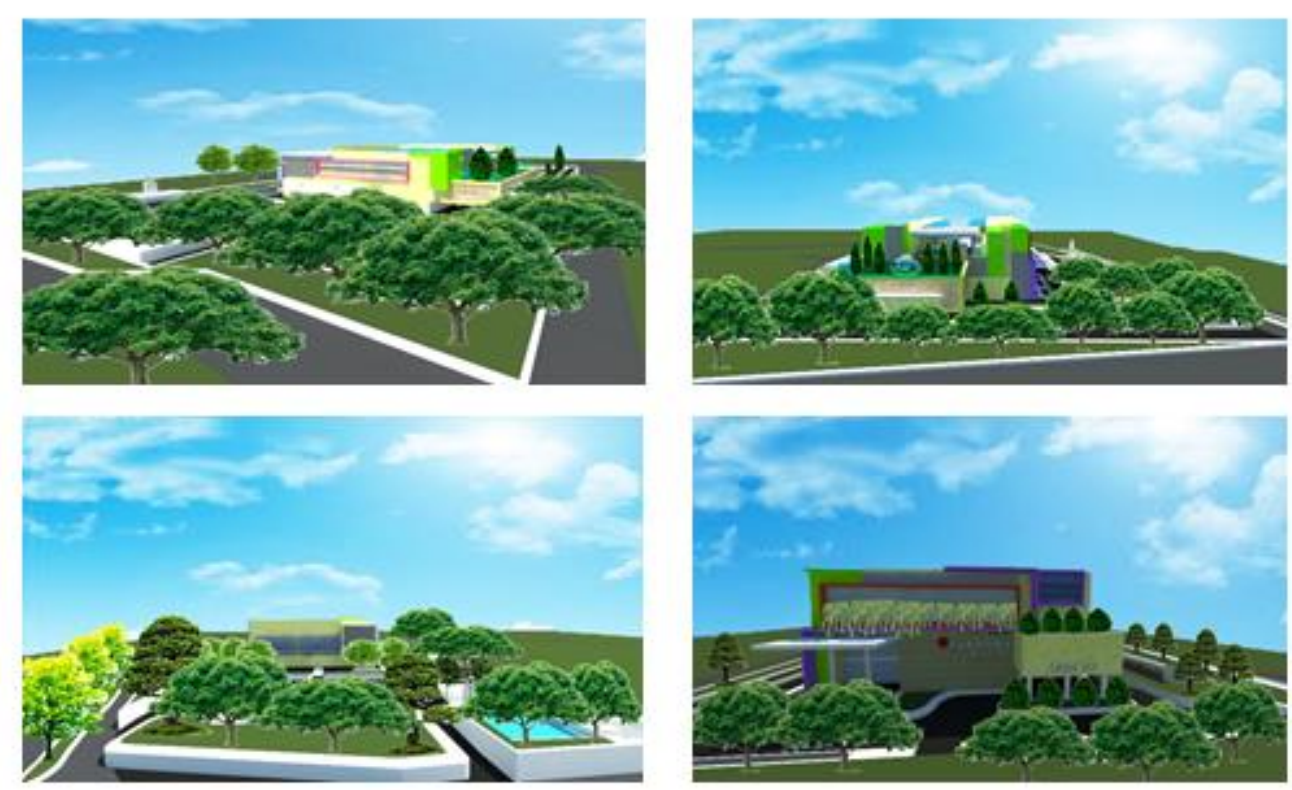

Gambar 9. Gambar Perspektif Exterior 


\section{SIMPULAN}

Pembangunan Rumah Sakit Umum Kelas B berkonsep Healing Environment di Kecamatan Cileungsi berguna untuk memenuhi fasilitas kesehatan di Kecamatan Cileungsi, Konsep Healing Environment merupakan solusi desain arsitektur yang dapat membantu penyembuhan pasien lewat lingkungan yang akan berpengaruh pada psikis pasien agar kesehatan dapat pulih kembali. Dengan pencapaian tersebut sangat diharapkan Rumah Sakit Umum Purnama ini dapat berkembang seiring dengan berkembang nya pertumbuhan penduduk di Kecamatan Cileungsi.

\section{DAFTAR PUSTAKA}

GRS, (2010).“Arsitektur Rumah Sakit”. Yogyakarta : PT.Global Rancang Selaras

Mulyandari, H. (2011). "Pengantar Arsitektur Kota". Yogyakarta: Andi.
Murphy, J. (2008). The Healing Environment. Website : www.arch.ttu.edu

Neufert, E. (1996). Data Arsitek. Jilid 1. Jakarta : Erlangga.

(2003). Data Arsitek. Jilid 2. Jakarta : Erlangga.

Peraturan Menteri Kesehatan R.I Nomor 340/MENKES/PER/III/2010 tentang Klafisikasi Rumah Sakit.

Surat Keputusan Menteri Kesehatan RI No. 983/MENKES/SK/XI/92 tentang Pedoman Rumah Sakit. Undang-Undang Republik Indonesia No. 44 Tahun 2009 tentang Rumah Sakit.

Wang, Z, (2012) "World Architecture 6Hospital Building". China : JTart Publishing Media 